This manuscript has been accepted by IEEE for publication (C) 2007 IEEE. Personal use of this material is permitted. Permission from IEEE must be obtained for all other uses, in any current or future media, including reprinting/republishing this material for advertising or promotional purposes, creating new collective works, for resale or redistribution to servers or lists, or reuse of any copyrighted component of this work in other works. The full reference is:

\title{
Implementation of a solution to the problem of dry-band arcing on ADSS cables
}

IEEE Trans PDel 22 Issue 1, (2007) 703-709

$S$ M Rowland, O de la Cerda, N R Haigh

DOI: 10.1109/TPWRD.2006.881600 


\title{
IMPLEMENTATION OF A SOLUTION TO THE PROBLEM OF DRY-BAND ARCING ON ADSS CABLES
}

\author{
Simon M. Rowland, Osvaldo de la Cerda, Neil R. Haigh
}

\begin{abstract}
The all-dielectric self-supporting (ADSS) cable offers many advantages when installing an optical fibre network on high voltage overhead lines. Generally the use of ADSS cables is confined to system voltage levels well below $275 \mathrm{kV}$ because of the threat of dry-band arcing on the cable sheath. This limit is somewhat arbitrary since in polluted conditions cables can fail at much lower system voltages, and in some higher voltage installations no problems have been witnessed. A solution to the problem of dry-band arcing on ADSS cables has been proposed previously, whereby $50 \mathrm{~m}$ resistive rods are attached to the selfsupporting cable after installation. The first large-scale installation of this system has been successful, and the first six years' operation is reviewed. The installation is in a particularly aggressive situation and a high level of maintenance has been found to be necessary.
\end{abstract}

Index Terms - Application, ADSs, cable, dry-band arcing, maintenance, optical, retro-fit solution

\section{INTRODUCTION}

The use of non-metallic optical cables that are strung directly from towers of high voltage overhead lines (alldielectric self-supporting or ADSS cables) is widespread. This is one of a number of cable designs which has successfully been used to deploy optical fibre on high voltage overhead lines [1]. The location of such a cable on a tower is shown in Fig. 1. One limitation of the use of ADSS cables is that induced currents on their surface can give rise to dry-band arcing in areas of high pollution [2]. Considerable improvements have been made to the performance of ADSS cables, by the development and use of sheath materials that are resistant to dry-band arcing [3,4]. Some attempts have also been made to manufacture cable with a controlled degree of conductivity [5]. Other techniques have been suggested [6], but as far as the authors are aware have not been tried commercially.

Manuscript received November 20, 2005

S. M. Rowland is with The University of Manchester, PO Box 88, Manchester, M60 1QD, UK: phone: +44 161306 4720; (e-mail: s.rowland@manchester.ac.uk).

O. de la Cerda is with Entel Chile SA, Amunategui 20, Piso 14, Santiago, Chile (e-mail: Odelacerda@entel.cl).

N. R. Haigh is with Lucid Optical Services, Garsdale, Sedbergh, Cumbria, LA10 5PE, UK. (e-mail: neil@blueside.freeserve.co.uk).
The most widely used product improvement is the 'arcresistant' sheath. These sheath materials certainly improve the performance of cables and extend the product life. However two key issues remain: firstly, it is not possible to forecast a cable's life expectancy in any given environment, although some degree of risk can be defined; secondly, a large volume of cable has been installed and some of this appears to be at risk. Problems of this nature tend not to be reported due to commercial sensitivity, but this paper and others may be indicative of a wider issue [7]

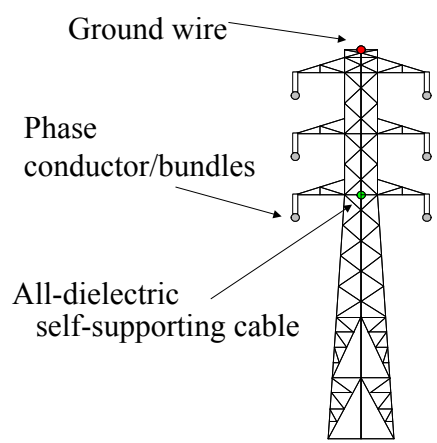

Fig. 1. Typical location of ADSS cable on the lower cross arm of a twin circuit tower.

An alternative solution, which has had extensive trials, is based on a rod of controlled resistance which is attached to the first $50 \mathrm{~m}$ of cable, adjacent to each supporting tower. This solution, known as the arc arrest system (AAS), has been deployed at an exceptional location where sheath damage has occurred only six months after ADSS cable was originally installed. The detailed application engineering behind the design is presented in a separate publication [8]. Here, the installation of the system is described, with a review of the performance of the system after six years' experience. As far as the authors are aware this is the only solution that has been successfully applied to a situation where the problem of dryband arcing has occurred with any severity.

\section{THE ORIGINAL INSTALLATION}

In November 1997, ENTEL, a telecommunications company in Chile, installed all-dielectric self-supporting (ADSS) cable on $110 \mathrm{kV}$ and $200 \mathrm{kV}$ lines owned by the 
power utility company Edelnor. The cables had a polyethylene sheath and were supplied by a number of multinational manufacturers to a similar design, all employing aramid yarn as the strength element. The ADSS cables were installed in the normal fashion [1] with both concrete poles and lattice towers on various parts of the routes. A number of suppliers provided cable for installation in an environment which did not appear to pose a significant threat according to the heuristics used at that time.

In April 1998, dry-band arcing damage was clearly evident on the cable on parts of the route. In the majority of cases, the sheath damage was due to relatively severe dry-band arcing near the towers. In some cases gaps of up to $3 \mathrm{~cm}$ had been created on the outer sheath. Figs. 2 and 3 show typical problems. Fig. 4 shows an extreme example, in which the cable had to be replaced. In this picture the aramid yarns have been broken and the tubes containing the optical fibres exposed. Three issues had combined to make this route a particularly onerous one for ADSS cables: firstly there is very little rainfall, secondly there is a great deal of salt spray from the sea, and finally there is regular heavy morning dew. Thus, there is regularly high conductivity precipitation on the cable and it is rarely cleaned by natural rainwater. In addition some of the lines are in close proximity to a cement factory which adds solid pollutants to the atmosphere. Fig. 5 gives an indication of the level of pollutant to be found on the cable surface. Another indicator that the environment is severe is given by the need to regularly wash the insulators on the same HV lines, and the lack of natural vegetation.

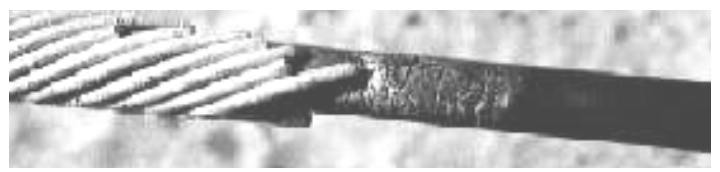

Fig. 2. Damage on a polyethylene sheathed cable on $100 \mathrm{kV}$ line in Chile. The metallic wires on the left are part of the cable clamping system at the tower.

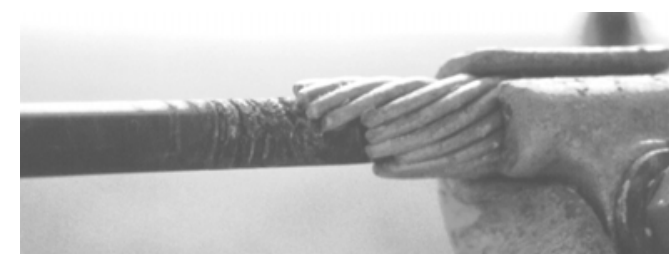

Fig. 3. Damage on a polyethylene sheathed cable in Chile on a $100 \mathrm{kV}$ line. The metallic wires are part of the clamping system and the galvanised clamp around those wires attaches the vibration damper.

The damage seen here may be compared to that reported on ADSS installations in Israel [7] and other sites [9,10]. The environmental similarity between the sites in Israel and Chile are clear. It was also noted that in England the worst case activity occurred at the end of a prolonged dry period in the summer months.

The overhead lines of concern here are bordered by the Pacific Ocean to the west. To the east, in a north-south direction, is the Cordillera mountain range which runs parallel to the Andes. The lines lie within the Atacama desert, which extends southwards for about $1,100 \mathrm{~km}$ southwards from the border with Peru to the north. The desert consists chiefly of a series of salt basins and is one of the driest areas in the world. The weather can be very cloudy and the humidity rises between $9 \mathrm{pm}$ and 7 am on a daily basis. Heavy dews can occur. The worst damage was witnessed on the lines closest to the sea and those crossing valleys where the wind had been funneled up from the sea.

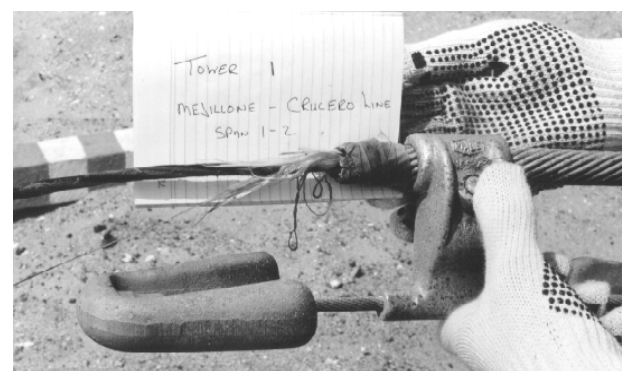

Fig. 4. Complete failure of the cable sheath and exposure of the strength member.

Fig. 5. Wiping the cable with a white glove gives some idea of the level of

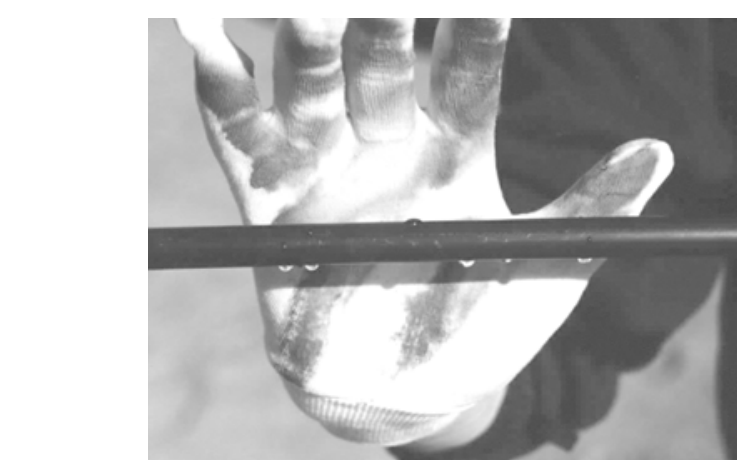

solid pollution on the cable in Chile.

At their closest the lines are $600 \mathrm{~m}$ from the ocean, and are $1 \mathrm{~km}$ to $2 \mathrm{~km}$ from the coast for long stretches (tens of $\mathrm{km}$ ), and here remedial work was required immediately. At one location there is both a coal-fired power station and an explosives factory within $500 \mathrm{~m}$ of the line, and in another the line passes close to a concrete factory. The line also crosses a rubbish tip inland from Antofagasta. In this area, the cable will be affected by both moisture and particulates from the sea and land, including pollution from the city, burning rubbish, and dust produced by waste crushers.

The power system requires the insulators to be washed on a two-monthly basis to remove salt deposits. Cleaning of the insulators on such a regular basis is indicative of a system suffering from the build up of electrolytes, allowing high leakage currents to occur. The frequent washing of the insulators has also led to the removal of the salt deposits from the ADSS cable close to the tower, which will form highly resistive regions where the cable is at most risk from dry-band arcing. 


\section{Classifying Damage And First Remedial Actions}

A method for classifying the dry-band arcing damage into four grades has been adopted to record the level of damage on the cables. This grading method is listed in Table I. Prior to the AAS being installed, and within six months of the ADSS cable being installed, damage up to grade 3 could be seen on many cable spans adjacent to the towers (Fig. 6). In these cases self-amalgamating, semi-conductive tape was applied over the damaged section of the cable and up to $3 \mathrm{~m}$ from the tower, and non-conducting, arc-resistant tape applied beyond these points to cover the damage. However, some damage of grade 4 level had been seen. In the example shown in Fig. 7, the grade 4 damage has occurred after the semiconductive tape was applied, and the tape can be seen on the left-hand side of the cable. Grade 4 damaged cable had to be replaced. The resistivity of the contaminants on the ADSS cable at such locations was crudely measured to be approximately 500 $\mathrm{k} \Omega / \mathrm{m}$. At some towers the sheath had been penetrated and retracted revealing the aramid yarn, the aramid yarn strength member being completely destroyed, exposing the PBT tubes containing the optical fibres (Fig. 4).

TABLE I

THE CLASSIFICATION METHOD USED TO RANK DAMAGE TO THE CABLE SHEATH

\begin{tabular}{|c|l|c|}
\hline Grade & \multicolumn{1}{|c|}{ Description (see also Figs. 6 and 7) } & $\begin{array}{c}\text { Radial } \\
\text { Depth }\end{array}$ \\
\hline 1 & $\begin{array}{l}\text { The surface of the sheathing material is discoloured } \\
\text { (this effect is called "chalking", possibly due to the } \\
\text { fillers leaching to the surface, and is indicative of } \\
\text { low level electrical activity) }\end{array}$ & $<0.1 \mathrm{~mm}$ \\
\hline 2 & $\begin{array}{l}\text { Material is partially eroded from the sheath due to } \\
\text { dry-band arcing }\end{array}$ & $<0.5 \mathrm{~mm}$ \\
\hline 3 & $\begin{array}{l}\text { Material is substantially eroded from the sheath due } \\
\text { to dry-band arcing }\end{array}$ & $<1.0 \mathrm{~mm}$ \\
\hline 4 & $\begin{array}{l}\text { Sufficient material is eroded to compromise sheath } \\
\text { integrity, exposing the aramid yarns to the } \\
\text { environment }\end{array}$ & $\geq 1.0 \mathrm{~mm}$ \\
\hline
\end{tabular}

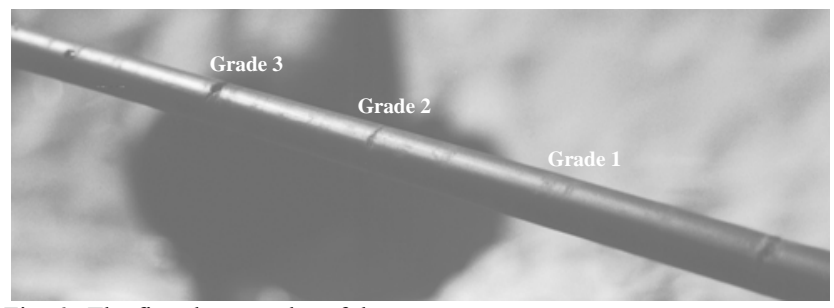

Fig. 6. The first three grades of damage.

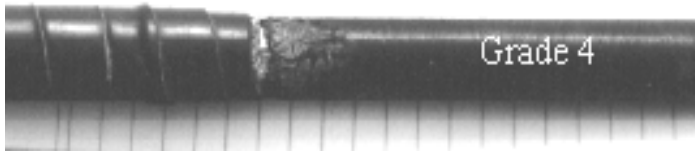

Fig. 7. The fourth grade of damage.

Software was used to predict the scalar potential with the ADSS cable located at the actual installation location. Previously this software has been validated by direct measurements on $400 \mathrm{kV}$ lines [11]. Potentials between the values of $7 \mathrm{kV}$ and $11 \mathrm{kV}$ were predicted. All of these values could have been reduced by repositioning the cable or changing the relative sags between the conductors and the ADSS cable, however, because the risk was not appreciate at the time of installation, the ADSS cables had not been installed in the optimum position to reduce induced currents. Fig. 8 shows a steel-reinforced concrete support, and the location of the attachment of the ADSS cable to the tower is highlighted. Fig. 8 also shows the insulator washing in progress.

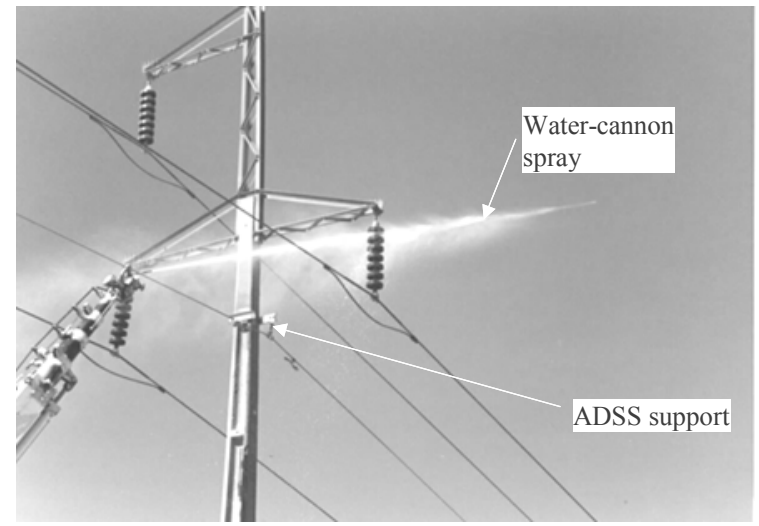

Fig. 8. A $110 \mathrm{kV}$ single circuit line supporting an ADSS cable. The water canon is washing the insulators.

\section{OVERVIEW Of THE RETROFIt ROD SOLUTION}

The Arc Arrest System (AAS) developed consists of the following components:

o The retro-fit rod, which consists of a resin-bonded glass strength member coated in an extruded, carbon-loaded resistive polymeric material

o A specially designed galvanised steel split clamp, attached over the ADSS cable clamp armour rods, to fix the rod to the cable clamp at the tower. The rod is held in the clamp using a semi-conductive polymeric material as a cushion.

o Semiconductive clips, to attach the rod to the cable span. The clips are spaced $0.3 \mathrm{~m}$ apart to allow: a good mechanical connection to the rod; easy installation of the rod and good electrical connection to the cable.

o A specially designed clip used to terminate the rod at its tip.

The resistive rods are normally fitted onto the ADSS cable in situ, by installation crews standing on ladders alongside the ADSS cable on the tower. Alternatively this can be done from a cherry picker on LV routes. Each rod is manually pushed towards mid-span, and clips are applied. The rods are sufficiently stiff to allow well over $50 \mathrm{~m}$ to be pushed into the span. They are pre-cut to length and supplied to site in coils. Because the ADSS cable is tensioned before the rod is attached, the majority of health and safety issues are easily overcome and live-line installation is not inhibited. However, 
an earth is required on the resistive rod during installation. If the rod is not efficiently earthed at the tower end during installation, it will float to a substantial potential and may deliver up to a few milliamps at several $\mathrm{kV}$, to installation personnel. To overcome this, a split open-ended tube forms a running installation 'bazooka' earth, as shown in Fig. 9. This running earth is designed so that three of the conducting clips are in contact with the earth at all times. Any exposed ADSS cable within reach of an operator from the tower will be wrapped in earthed metallic spiral guard wire, which is an inherent part of the ADSS clamp. The 'bazooka earth' must also be used when the product is removed from service, but it is not required during the operational life of the cable; nor is it required if the rod is installed or removed with the circuits switched out. The installation process is shown on a $400 \mathrm{kV}$ line in the UK in Fig. 10. Fig. 11 shows the process preferred in Chile using a cherry-picker.

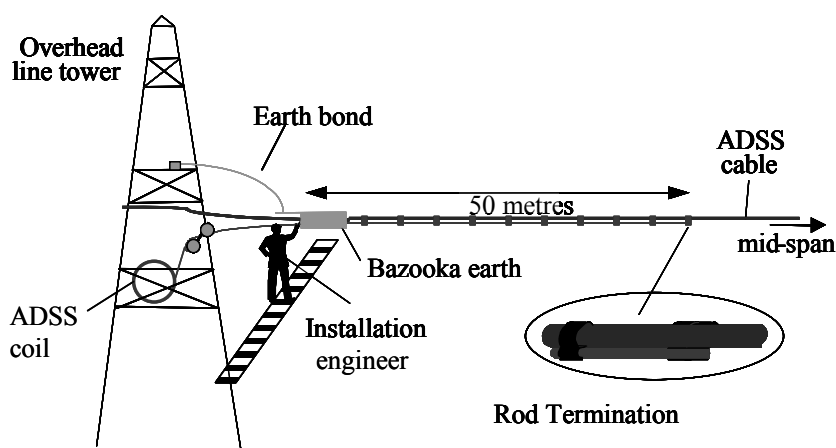

Fig. 9. Schematic of the rod installation.

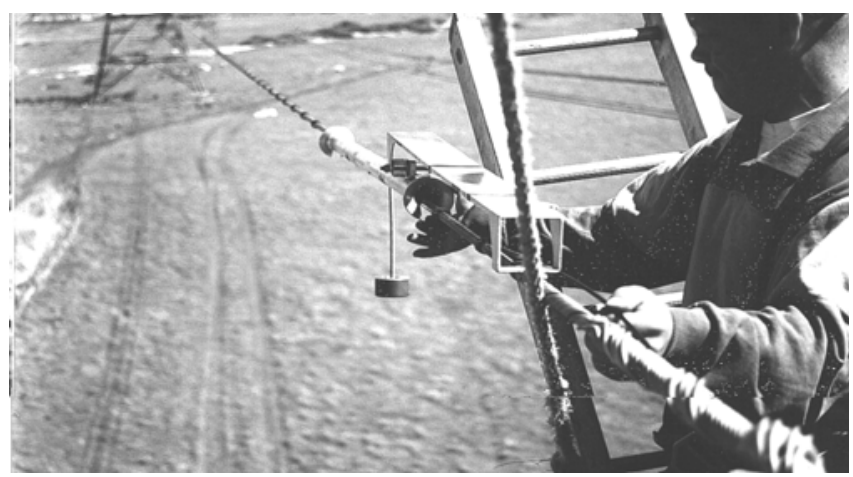

Fig. 10. An installation on a $400 \mathrm{kV}$ tower in the UK. The linesman's righ hand is touching the split-tube running earth, his left hand is pushing the rod into the span; he attaches clips between these positions.

The origin of the damage to ADSS cables is the distributed capacitances between the optical cable, the phase conductors, the earth wires and ground, which results in a voltage gradient along the dielectric cable's length. If the cable is dry, the voltage gradient does not present a problem. However, if the cable surface becomes conductive, due to moisture and the presence of pollution, a current is drawn along its length. The current is greatest at the tower, where the cable is clamped and at earth potential. This current will tend to dry the cable surface, inevitably leading to a first break in the previously continuous conductive surface. This break presents a dry band across which significant voltages can be dropped, leading to dry-band arcing. Such arcing can be sufficient to degrade a cable sheath, through melting, formation of carbon tracks or erosion.

Application of the rod prevents damage to the cable in two ways. Firstly, it prevents high fields being built up over the ADSS cable over the region on which it sits, thus preventing dry-band arcing occurring in that region of the cable closest to the tower. Secondly, as can be seen from Fig. 12, the current diminishes away from the tower, and if the rod is long enough, the current beyond its length is too small to sustain a damaging arc. The presence of the rod clearly influences the currents and voltages, and when the rod is present, a current flows along its length even when the cable is dry. Thus managing the Joule heating in the rod and any resulting heating is a critical design requirement. The key parameters when designing a system are keeping the current on the cable at the rod tip to an acceptable value (typically $0.1 \mathrm{~mA}$ for a polyethylene sheathed cable), and preventing the current in the rod at the tower being excessively high when the rest of the cable is heavily polluted. This is discussed at length elsewhere [8].

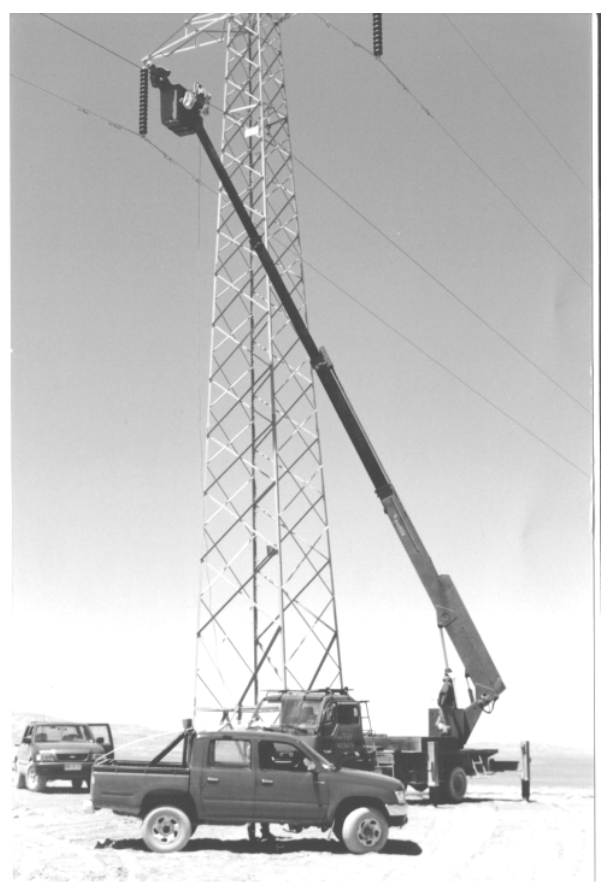

Fig. 11. An installation in Chile using a cherry-picker. This approach was used on all lattice towers.

In addition to the design of the system, the manufacture of the resistive rods is key to the success of the application. If the rods are too conductive, insufficient voltage will be dropped over their length to stop aggressive dry-band arcing at their ends. If the rods are too resistive they will not prevent dry-band arcing within their length. Moreover, if a small fraction of a rod length is very resistive, thermal ageing or runaway may occur within the rod at this point, creating a 
bigger problem than existed before the rod was deployed. For this reason the resistance of every metre of rod manufactured is measured and recorded, prior to cutting and shipping.

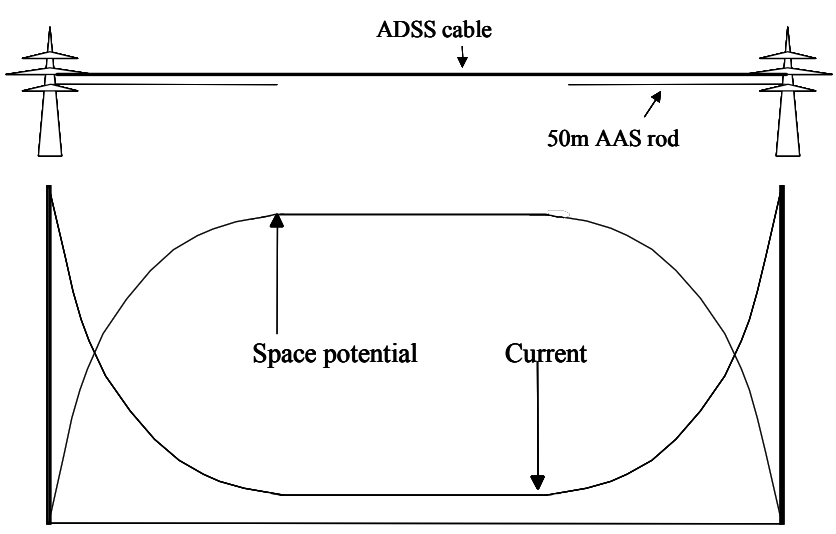

Fig. 12. A schematic of the distribution of voltage over the cable and rod system. Also shown is the cumulative current over the cable surface, which is maximum at the tower. The conductors are not shown in the figure.

\section{Full Scale Trials AND TyPe TESTING}

The Arc Arrest System development has included an extended set of trials on a $400 \mathrm{kV}$ double circuit power line at Dungeness in Kent, England, between 1996 and 2000. This has been reported elsewhere [8,10,11]. During the period of the trial, currents were monitored on the system and compared to those predicted by a software model. Over this period a number of sheath materials were examined and the performance of different rod resistances and lengths verified. Compared with the situation in Chile, Dungeness has much higher rainfall and so pollution is less onerous. However, in Dungeness the field in which the cable was hung was considerably greater. Thus the currents experienced in each case were similar. Through the various installations at Dungeness, learning what did and did not protect cables, and fully verifying the software developed to model the potentials and currents in the system, confidence was developed in understanding the system and its performance.

Details of engineering analysis are given in [8]. Such an analysis must be performed with the worse-case environment and judging this is the most difficult task involved. In the case of Dungeness, extensive measurements of cable resistance were made over the period of the trials. Normally measuring the pollution on a system is not an easy option [12]. Table II shows how some of the design parameters vary with rod resistance. In this case the relative sags between the ADSS cable and the conductors have been held constant. The criticality of the choice of rod resistance can be seen from this work. In this case only a very high resistance rod would be able to prevent currents at its tip from being too high. The $0.17 \mathrm{~mA}$ predicted at the tip of a $2200 \mathrm{k} \Omega / \mathrm{m}$ rod is probably enough protection for a polyethylene cable. However, if a $1100 \mathrm{k} \Omega / \mathrm{m}$ rod was deployed, the $0.23 \mathrm{~mA}$ current would provide enough energy in an arc to damage a polyethylene sheathed cable. In fact a standard 'dry-band arc resistant' sheath material would be protected at this current, so such a rod would be satisfactory only on such a cable [8].

TABLE II

KEY PARAMETERS CALCULATED FOR A SPAN AT DUNGENESS. THE ROD LENGTH WAS $50 \mathrm{~m}$. THE CABLE RESISTANCE WAS TAKEN AS $2000 \mathrm{k} \Omega / \mathrm{m}$.

\begin{tabular}{|l|l|l|l|l|}
\hline Retro-fit rod resistance $(\mathrm{k} \Omega / \mathrm{m})$ & 2200 & 1100 & 900 & 400 \\
\hline Total current at tower, system wet $(\mathrm{mA})$ & 1.03 & 1.24 & 1.33 & 1.77 \\
\hline $\begin{array}{l}\text { Maximum power in rod when system } \\
\text { wet }(\mathrm{W} / \mathrm{m})\end{array}$ & 2.3 & 1.7 & 1.6 & 1.25 \\
\hline Maximum field along rod $(\mathrm{kV} / \mathrm{m})$ & 2.3 & 1.4 & 1.2 & 0.7 \\
\hline Total current at tower, system dry $(\mathrm{mA})$ & 0.64 & 0.96 & 1.08 & 1.70 \\
\hline Continuous power generated in rod $(\mathrm{W} / \mathrm{m})$ & 0.9 & 1.0 & 1.0 & 1.2 \\
\hline Current at rod tip when system wet $(\mathrm{mA})$ & 0.17 & 0.23 & 0.26 & 0.39 \\
\hline
\end{tabular}

\section{Commercial Deployment Of ArC Arrest System}

The currents induced on the unprotected ADSS cable were analysed. Assuming the resistivity of the cable to be of 500 $\mathrm{k} \Omega / \mathrm{m}$, currents were calculated to be between $0.4 \mathrm{~mA}$ and $0.75 \mathrm{~mA}$ at the towers. These results would indicate that grade 3 damage should have occurred within 6 months of installation, as seen in some cases. This rate of failure has not been observed over the entire line. The observed rate of failure would imply that the resistivity over much of the line is greater than $1,500 \mathrm{k} \Omega / \mathrm{m}$. For each span, installation of the cable in the best location and optimum sag could lead to a significant reduction in the induced current, however the reduction in the induced current is not sufficient, and is still above the acceptable level for the polyethylene sheathed ADSS cable in many cases.

To ensure the results at Dungeness correlate with the conditions in Chile, three trial sections of the AAS were installed in $25 \mathrm{~m}, 50 \mathrm{~m}$ and $150 \mathrm{~m}$ lengths during May 1998. Damaged sections of the cable sheath were repaired with a semi-conducting, self-amalgamating tape up to $1.5 \mathrm{~m}$ from the tower to waterproof the cable. Three months later inspection revealed that the semi-conductive tape repair alone did not work, as although no further damage was reported on the taped area, the tape simply transferred the electrical activity to beyond the end of the repaired section, Fig. 7. The inspection also revealed that the lines protected by $50 \mathrm{~m}$ and $150 \mathrm{~m}$ AAS rods showed no new damage. The $25 \mathrm{~m}$ rod gave the impression of reducing the level of damage but was not completely effective. This was in line with the expectations of the design team.

On the $110 \mathrm{kV}$ towers, a $50 \mathrm{~m}$ rod of standard resistance per unit length provides the limiting rod-tip current for the polyethylene sheathed cables $(0.1 \mathrm{~mA})$ for pollution of around $400 \mathrm{k} \Omega / \mathrm{m}$. This gives a 'wet tower' maximum current of 0.48 $\mathrm{mA}$ and maximum power in the $\operatorname{rod}$ of $0.1 \mathrm{~W} / \mathrm{m}$, which presents no problem. The model predictions of rod tip current are summarised in Table III.

TABLE III 
VARIATION OF ROD-TIP CURRENT WITH A POLLUTED CABLE OF $400 \mathrm{k} \Omega / \mathrm{m}$, AS A $50 \mathrm{~m}$ ROD RESISTANCE IS VARIED.

\begin{tabular}{|l|l|l|l|l|l|l|}
\hline Rod resistance $(\mathrm{k} \Omega / \mathrm{m})$ & 400 & 600 & 800 & 1000 & 1300 & 3000 \\
\hline $\begin{array}{l}\text { Rod tip current }(\mathrm{mA}), \\
220 \mathrm{kV} \text { lines }\end{array}$ & 0.21 & 0.19 & 0.18 & 0.17 & 0.16 & 0.15 \\
\hline $\begin{array}{l}\text { Rod tip current }(\mathrm{mA}), \\
110 \mathrm{kV} \text { lines }\end{array}$ & 0.14 & 0.11 & 0.09 & 0.08 & 0.07 & 0.05 \\
\hline
\end{tabular}

On the $220 \mathrm{kV}$ towers the rod end current is uncomfortably high, around $0.22 \mathrm{~mA}$ for standard rods, so higher resistance rods are selected for the more onerous locations, or the cables have to be repositioned or re-sagged to reduce the current.

In December 1998, installation of the AAS began on 100 $\mathrm{km}$ (700 towers) of the worst affected line sections. Within two months of installation it was found that a large number of clips were failing at their hinges due to high levels of UV radiation and high ambient temperatures. Temporary remedial action was taken and new clips were then rapidly developed using an alternative material. A final section of cable was also retro-fitted with rod in October 1999. In a few extreme cases the ADSS cable was replaced.

In total $20 \mathrm{~km}$ of line on 408 lattice steel towers carrying $220 \mathrm{kV}$, and $87 \mathrm{~km}$ on concrete poles carrying $110 \mathrm{kV}$ were protected. The rods were installed at 50 spans per week and it was found that where the ADSS cable had been installed on concrete posts, it was possible to lower the cable to the ground to perform the installation of the AAS. Using this method, ten towers where typically installed per day. On tension posts, rail / road / lower voltage line crossings and steel towers this installation rate was reduced to 4 to 6 towers per day.

\section{POST INSTALLATION EXPERIENCE}

The installations have been inspected routinely. At the time of writing, over six years have passed since the original installation, and the system is still running. Inspections at the tip of the rod have shown no evidence of dry-band arc activity. However, close to the towers there are clear visual indications that the rod is not performing as expected. In many cases arcing is occurring after a period of time close to the towers. Figs. 13 and 14 show the form of damage seen. It can be seen that the semiconductive sheath of the rod is becoming aged, and in Fig. 13 clear evidence is seen of dryband arc activity at such a location. The closer inspection of Fig. 14 shows classic dry-band arc degradation patterns on the cable sheath.

Fig. 15 shows damage that has occurred as a result of arcing between a rod and a previously applied repair sleeve. This has resulted because the rod and semiconductive tape repair have only been electrically connected at the cable clamp, and so a potential difference can occur between the two where the tape ends, because of their different linear resistances. This can be prevented by binding the rod to the semiconductive tape at the span-side end of the taped region.

Fig. 13. Damage can be seen on the cable to the right-hand side of the right cable clip.
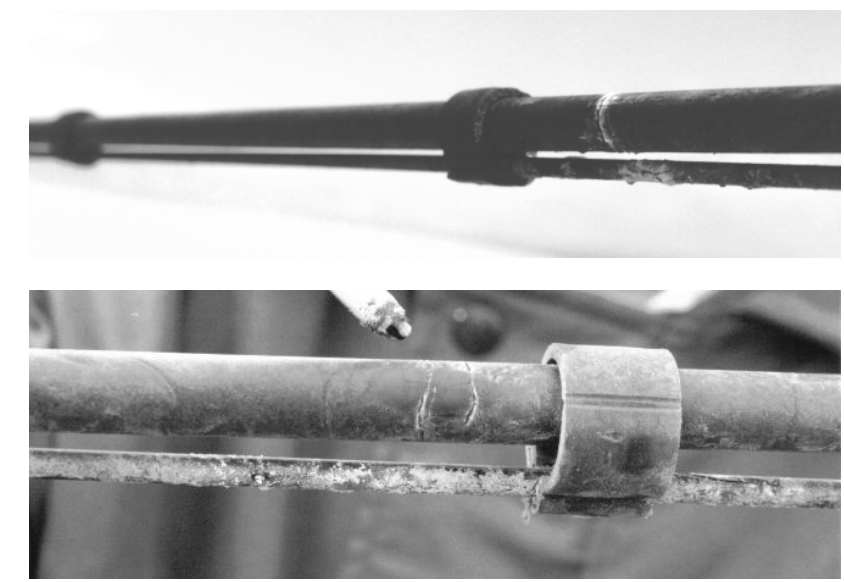

Fig. 14. Damage on the cable and rod can be seen. The clip used here is for a larger sized cable, and is too loose on the ADSS cable.

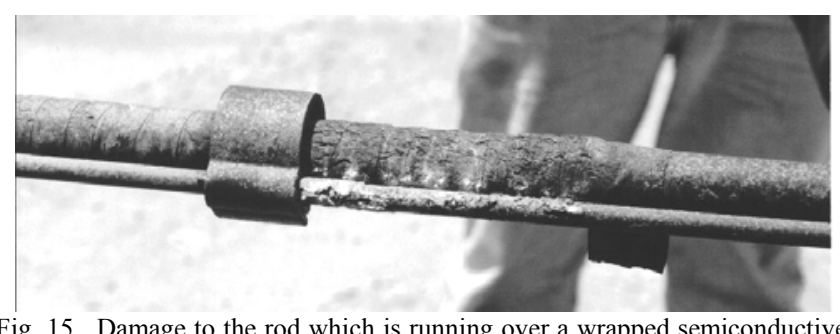

Fig. 15. Damage to the rod which is running over a wrapped semiconductive repair sleeve.

The rod is clearly ageing close to the clamp much faster than was predicted, although it does continue to protect the cable for long periods of time. As a result the AAS system remains the only known way to protect the cable in these circumstances. A regular inspection and maintenance schedule is now in place for the installed system. Any visual evidence of ageing of the rod close to the tower, or evidence of arc activity on the cable sheath now results in the section of rod closest to the tower being cut back and the rod reterminated.

The present maintenance regime generally results in each rod being cut back once every 6 years. In particularly onerous conditions this is exceeded, and frequent shortening of a rod will require its replacement in time.

\section{DISCUSSION}

When considering the use of ADSS cables on HV transmission lines, calculating the mid-span potential is not in itself enough to determine the severity of the situation. In the case studied here that potential was less than $10 \mathrm{k} \mathrm{V}$, but the extreme environment created adverse circumstances, certainly too severe for a polyethylene sheath to survive. With hindsight two indicators that the environment is severe are the need to regularly wash the insulators on the same HV lines, and the lack of natural vegetation underneath the lines.

The geographical region in which the cable sits, adjacent to the sea, is certainly a major issue. It should be noted, however, that the locations close to cement factories and mines were most effected, and this is attributed to lack of 
rainfall to wash the cable clean of solid deposits. However since failure was so rapid it might be concluded that anywhere where rainfall is absent for only 6 months must be considered high risk.

That the insulators are washed has also led to speculation that one accelerating cause of failure is that the ADSS cable is inadvertently washed only adjacent to the support structures. This presents the possibility of encouraging dry-band arc activity by creating small regions of high resistance close to the tower, where dry-band will naturally form quicker than they would otherwise. Since such artificially produced clean regions have a high resistance, they will dry out rapidly while the rest of the cable is still very wet thus providing a higher current in an arcing condition for longer periods of time. Thus the need to wash insulators may not only be indicative of an aggressive environment generally, but the very act of washing the insulators may make the situation significantly worse for the cable, increasing the periods of dry-band arcing and also increasing the arc current.

The resistive rod used in this case has been designed without considering the added impact of the washing of the insulators and thus this increased threat of local washing. It is possible that washing a larger part of the ADSS cable would alleviate this, but this is not necessarily practical and has not been attempted. However, this may be the factor that turned a borderline design into one that needs active maintenance.

Certainly more research is required into the ageing characteristics of the rod in extreme circumstances. In this application the limiting factor was expected to be the current at the rod tip. The design suggested that this was on the borderline of acceptability for high reliability. In fact the current at the towers has been found to be the biggest issue for this case.

\section{CONCLUSION}

Two things might indicate a particularly aggressive environment for the deployment of ADSS cables: firstly, if there is little vegetation on the ground, this suggests low rainfall; and secondly if the local practice is to wash insulators, this suggests high levels of pollution can build up. The washing itself might also lead to an increased problem as it results in a high resistivity region adjacent to the towers. However, the impact of this is not clear. Certainly the limits to the use of ADSS cable based on mid-span potentials, suggested by IEEE P1222, are not appropriate in this case.

The arc arrest system described has been developed over an extensive period of time and been trialed over many years in the UK. Over $100 \mathrm{~km}$ of ADSS cable has been successfully protected in Chile in a very onerous environment. Since that installation, over a six-year period, AAS has been shown to work where previously ADSS cables had failed in less than six months. Moreover, the AAS worked as a retro-fit package on a standard polyethylene cable. Because of the extreme climate, the engineering was pushed to its limit and as a result high levels of maintenance have been required.

This system clearly provides a method of protecting existing and new ADSS cables in onerous environments where high currents are expected on the surface of the cable.

\section{ACKNOWLEDGMENT}

The authors would like to thank Corning Cable Systems and ENTEL for permission to publish the contents of this paper. The project would not have been completed without the excellent engineering and commitment of Andy McDowell.

\section{REFERENCES}

[1] Electric Cables Handbook, 3rd Edition, Ed G. F. Moore, Blackwell Science 1997, ISBN 0-632-04075-0. Part 7, “Optical Fibres in Power Transmission Systems," Chapters 47-52, pp. 685-752.

[2] C. N. Carter, "Dry band electrical activity on optical cables strung on overhead power lines," Proc. 37th International Wire and Cable Symposium, pp. 117-121, 1988.

[3] A. J. Peacock and J. C. G. Wheeler, "The development of aerial fibre optic cables for operation on $400 \mathrm{kV}$ power lines," IEE Proc. A, vol. 139, pp. 304-313, 1993.

[4] S. M. Rowland, "Sheathing materials for dielectric, aerial, selfsupporting cables for application on high voltage power lines," 6th IEE Conference on Dielectric Materials, Measurements and Applications, pp. 53-56, 1992.

[5] U. H. P. Oestreich and H. M. Nassar, "Self-supporting dielectric fibre optical cables in high voltage lines," 37th Proc. International Wire and Cable Symposium, pp. 79-82, 1988.

[6] C. N. Carter, "Arc controlling devices for use on self-supporting, optical cables," IEE Proc. A, vol. 140, pp. 357-361, 1993

[7] F. Kaidanov, R. Munteanu, G. Sheinfain, "Damages and destruction of fiber optic cables on $161 \mathrm{kV}$ overhead transmission lines," IEEE Electrical Insulation Magazine, vol. 16, pp. 16-23, 2000.

[8] S. M. Rowland, "Engineering a solution to the problem of dry-band arcing on ADSS cables," IEEE Trans DEI to be published ACCEPTED FOR PUBLICATION?

[9] G. Carlton, A. Bartlett, C. N. Carter and A Parkin, "UK power utilities' experience with optical telecommunications cabling systems," Power Engineering Journal Feb. pp. 7-14, 1995.

[10] C. N. Carter, J. Deas, N. R. Haigh, S. M. Rowland, "Applicability of alldielectric self-supporting cable system to very high voltage overhead power lines," 46th Proc. International Wire and Cable Symposium, pp. 624-631, 1997.

[11] N. R. Haigh, S. M. Rowland, A. J. Taha, and C. N. Carter, "A fully instrumented installation and trial of a novel all-dielectric selfsupporting cable system for very high voltage overhead power lines," 45th Proc. International Wire and Cable Symposium, pp. 60-67, 1996.

[12] G.G. Karady, H.Qi, M. Reta-Hernandez, D. Srinivasan, M. Tuominen, "Sensor design for leakage current measurement on ADSS fiber-optic cable," IEEE Power Engineering Society Winter Meeting, vol.1, pp. 281 $-286,2001$.

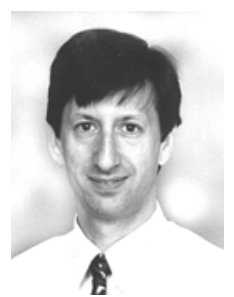

Simon M. Rowland was born in West Ham, London, England. He completed his BSc in Physics from The University of East Anglia and was awarded his PhD from London University in 1984. Dr. Rowland became a Fellow of the IEE in 2000, and was awarded the IEE Dudell premium in 1994. He has worked in industrial research on dielectric materials and their applications, and has been a Technical and Managing Director in a multinational manufacturing company. He has been a Senior Lecturer in the School of Electrical and Electronic Engineering in The University of Manchester, UK, since 2003. 

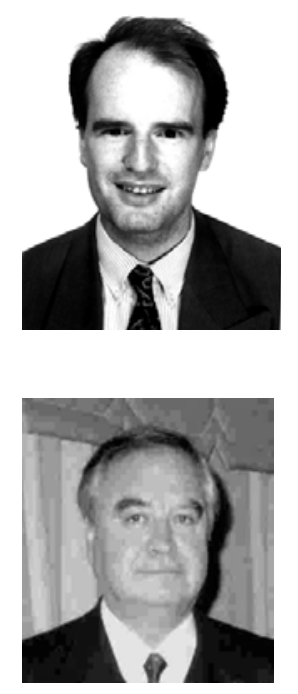

S.A.

Neil R. Haigh was born in Cheshire, England. He graduated with a BSc and $\mathrm{PhD}$ from the University of London, specialising in the field of Applied Optics. He joined Corning in 1988 specialising in optical fibre measurements. He was Project Manager for the HV ADSS cable development. He now works as a trainer for Lucid Optical Services.

Osvaldo de la Cerda was born in Santiago, Chile. He graduated as an Electronic Engineer from The Catholic University of North, Chile. He works as Project Manager in ENTEL S.A. (Empresa Nacional de Telecomunicaciones S.A.) and was responsible for the installation, operation and maintenance of the $2100 \mathrm{~km}$ of OPGW and ADSS cables of the North Path Network. He is a Senior Engineer and is the Project Director of the main project of SDH and DWDM network in Chile $(4.000 \mathrm{kms})$ for ENTEL 